was not ncarly so acute as in the first case related. An amount of partial obstruction had, however, existed for a considerable period; and this during the day or two preceding the operation had become complete.

I would strongly advocate the method of extraperitoneal suture as the safest, and that which is most free from anxiety. It is, however, not easy to strip up the peritoneum from the parietes to a sufficient extent without tearing it ; but slight rents may be closed with a continuous suture of fine silk. The suturing of the intestine is also more difficult, owing to the position of the ends of the intestine. It was especially so in the case reported, because the walls of the bowel were sodden and very friable; and $I$ had at the time considerable doubt as to whether the sutures would hold. They did not, in fact, do so completely, although the ultimate result was not affected.

REFERENCE.

1 Abdominal Surgery, vol. ii, p. 634

\section{A CASE OF ARRESTED DEVELOPMENT OF THE THIRD AND FOURTH RIBS.}

By ALFRED G. LEVY, M.D.LoND.

I FoUND this abnormality in a somewhat poorly-developed boy of 13 years of age. The general features of the case are as follows :

The front of the chest on the right side (Fig. I) presents a striking depression over the position corresponding normally

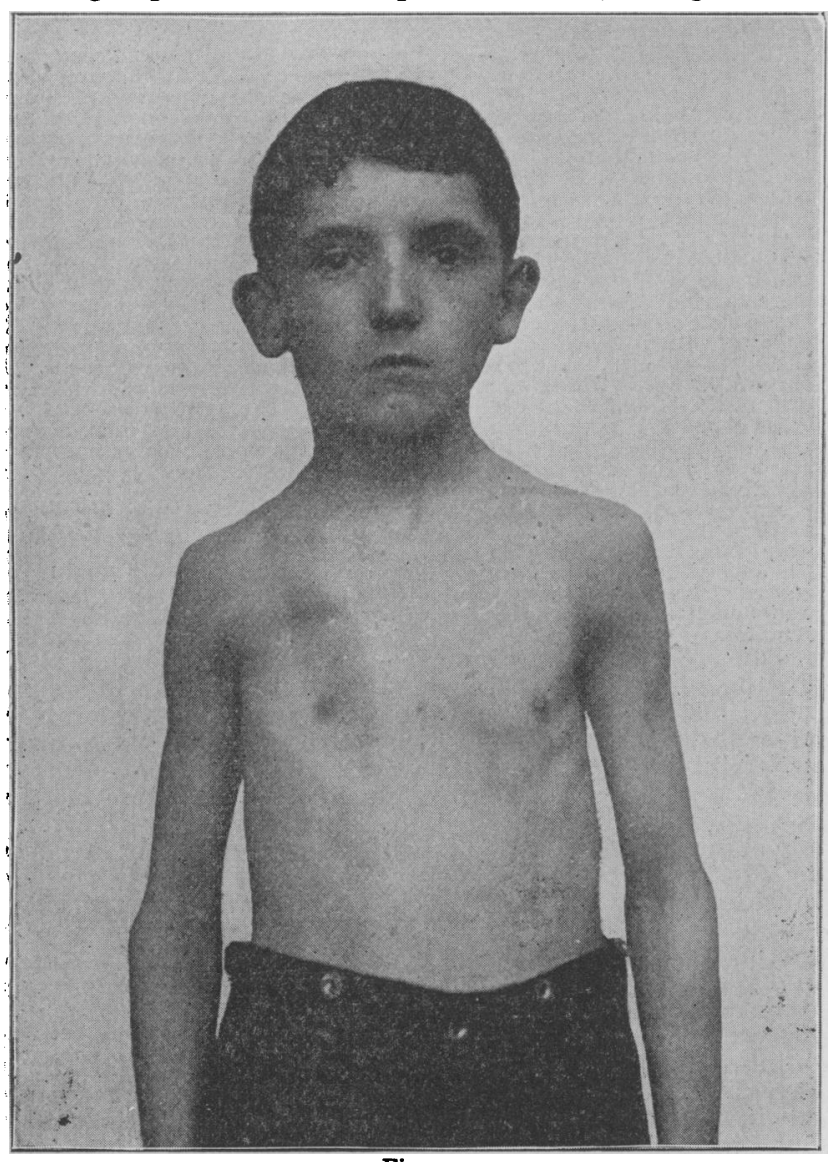

Fig. 1.

to that of the third and fourth ribs, and this appearance is accentuated by the exaggerated development of the clavicular portion of the pectoralis major, and of a small neighbouring portion arising from the first rib cartilage. There is no further trace of pectoral muscle, either major or minor.
The third rib cartilage is a little stump about half an inch in length, but the fourth is a narrow curved strip two-and-ahalf inches long lying close along the upper border of the nifth cartilage. The end of the curtailed third rib may be obscurely felt in the axilla just under the margin of the pectoral muscle and lying close to the second rib while the attenuated termination of the fourth rib is found a little further back in the axilla. The skiagraph, made

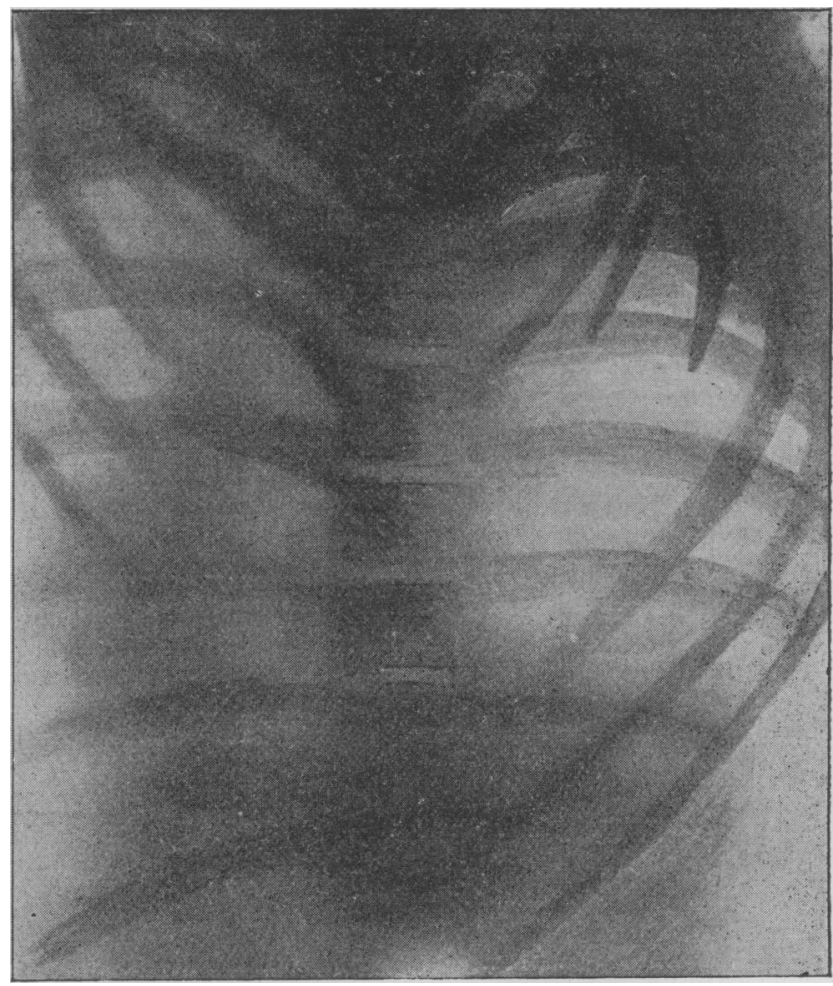

Fig. 2.

for me by Messrs. Coxeter and Son (Fig. 2), was taken with the boy lying in the prone position, so that it represents a front view of the thorax, and the tapering ends of the malformed ribs are seen in the skiagraph.

Naturally some spinal deformity results. There is a well marked dorsal curvature with little compensatory curve either in the lumbar or the cervical regions; this is the usual type of curvature found in cases of collapse of the ribs, such as may be found following an empyema, but whereas in the latter case the convexity of the curvature would be directed towards the healthy side, in the present instance the spinal column is deflected towards the malformed side, as perhaps might be expected from the deficiency of muscular and bony support involved therein. Judging from the breadth of the intercostal spaces on the two sides of the chest, there does not appear to be much rotation of the vertebræ, but it is probable that matters have been considerably modified by a systematic course of gymnastics which the patient underwent about a year ago with markedly beneficial results.

Abnormal conditions of the chest such as I have just described are decidedly rare. Now and again a case of complete absence of some of the ribs, usually the asternal ones, is reported, the condition being sometimes associated with imperfect development or absence of corresponding vertebræ; but it would certainly appear that ribs tend more to vary in the direction of complete absence than in that of mere incompleteness of development. The first rib is partly responsible for examples of the last-named deformity, but L. E. Hertslet states that only 5 cases of rudimentary first ribs are recorded in Great Britain, and $\mathrm{Helm}^{2}$ can find only 16 in the general anatomical literature of the past twenty-five years. Both of the above-mentioned authorities record cases, as also does 
Professor Struthers, ${ }^{3}$ who likewise mentions degrees of deficiency sometimes discovered in the twelfth pair.

In Förster's Missbildungen des Menschen the following paragraph is found: "Finally, clefts in the thorax may sometimes be caused by defects of the ribs, in that several ribs of one side may be wanting from the mid-point onwards, and the gap thus formed being closed by a firm membrane. It is the anterior portions of the ribs which are wanting, together with the rib cartilages. Sometimes the rib ends are not quite absent ; but the ribs, the posterior portions of which are perfect, are continued forward as riband-like bands."

Otto, in his Pathological Anatomy, also remarks upon the occasional deficiency of the attachment of the front ends of the true ribs, but the three cases to which he gives references differ materially from the condition which I have described. Of instances of similar deformities in the living subject $I$ find the following records: $(a)^{+} \mathrm{A}$ case presenting a longitudinal furrow between the six upper ribs of the left side and their cartilages; $(b)^{5}$ an infant in which all the ribs of the left side except the first two, which were perfect, were represented by short rudimentary processes; $(c)^{6}$ a case of a man in whom a depression "as big as the fist" on the left side of the chest was accounted for by the partial deficiency of the third, fourth, and fifth ribs on that side.

The rudimentary first ribs have been variously regarded as possessing developmental and even evolutionary significance, but instances of the retarded development of the other ribs are probably purely accidental faults, comparable to those occasionally found in almost all the other bones in the body.

It seems probable that the exact nature of this deformity may not be always readily recognised in the living subject without the aid of $x$-ray photography. It is not easy by digital examination alone to differentiate the somewhat obscurely felt tense membranous bands from bone, so that the condition may be quite readily mistaken for an acquired local incurvation of the chest wall.

\section{REFERENCES.}

Hertslet, Jour. Anat. and Phys., London, 1896, vol. xxx. ${ }^{2}$ Helm, Anat. Anz., Jena, 1804-5, p. 540. $3 \mathrm{~J}$. Struthers, Jour. Anat. and Phys., London, 1875, vol. ix. 4 Trans. Amer. Orthop. As\&oc., Philadelnhia, 1889, i1, p. 233

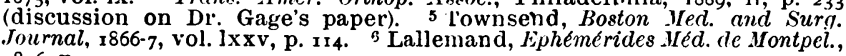
1826, p. 144 .

\section{A PARTIAL AMPUTATION OF TIIE FOOT.}

\section{By JOHN HERN, M.D., F.R.C.S.EDIN.,}

Surgeon, Darlington IIospital.

At the annual meeting of the British Medical Association at Edinburgh in August, I898, I showed to the Surgical Section a case in which I had performed partial amputation of the foot by a new method. The lines of incision in this amputation are practically those of Chopart's operation, the antero-posterior being preferable to the lateral flaps if they can be obtained.

The incisions are carried down to the bones, the lower flap being dissected back to the level of the medio-tarsal joint, the upper to that of the ankle-joint ; the foot is now forcibly depressed, the ankle-joint opened anteriorly, the lateral ligaments of the ankle-joint are next cut, also the strong calcaneo-astragaloid (interosseous) ligaments, and the whole tarsus, excepting the os calcis, removed. The os calcis is now drawn forwards between the malleoli, and is wired firmly in that position: one strand of wire passed obliquely through the lower end of the tibia and the anterior portion of the os calcis is usually sufficient. Care should be taken that the heel is in the direct line of the tibia. In some cases about $\frac{1}{4}$ to $\frac{1}{2}$ inch of the anterior portion of the os calcis was sawn off; in other it was found easier to doa Chopart first, then to seize the head of the astragalus with the lion forceps, and remove it by inserting the knife under it, and cutting the strong calcaneoastragaloid interosseous bands, and then proceeding as above described to bring forward the os calcis between the malleoli. The resulting stump is an excellent one ; it is broad and firm, consisting as it does of the heel practically unaltered.

The human foot mov be regarded as a tripod, the heel, the ball of the great toe, and the ball of the little toe being the three points at which the weight of the body is transmitted to the ground. Now, given an injury destroying all possibility of retaining both anterior points, the most satisfactory method of transmitting the body weight to the ground is through the heel alone, as done by this operation.

There is a broader stump than produced by Syme's amputation, and attended with less shortening and less shock. There is no tendency to drawing up of the heel and walking on the cicatrix, as in Chopart, for the enemy (tendo Achillis) is disarmed by the drawing forward of the os calcis, thus shortening the projection backwards of the heel and lessening the leverage.

An ordinary boot can be worn with comfort, and keeps well in shape if a steel plate be stitched into the sole and the sides of the boot stiffened or supported by light side irons and the front portion of the boot stuffed in some way.

\section{THE 'TREATMENT OF DYSENTERY.}

Br D. M. M. ROSS, M.B.,

\section{Wetheral.}

WHILE practising in Jamaica, I was on the whole disappointed with the results which ipecacuanha gave, finding it by no means the "radix antidysenterica," which it appears to be in India. In some cases, more particularly in European patients and in the early stages of the disease, its beneficial influence was marked, but in a number of these there was nothing to indicate that rest in bed, dieting, and mild aperients would. not have effected as desirable a result. The ordinary ipecacuanha powder of the $B$. $P$. appeared to be more efficient. than the preparation " sine emetine."

In negro patients the average results were more satisfactory from the magnesium sulphate treatment. In some of these, however, ipecacuanha was useful; in others the sulphate caused so much griping that its use had to be abandoned.

It may be that the difference in the results produced by ipecacuanha in the two races is dependent on the difference of their modes of life, more especially as regards diet, and its. effect on the functions of the liver.

The more I saw of the disfase the more did I feel that treatment had to be varied to meet individual peculiarities and the different stages through which the disease passes. It is most important that coexisting cachectic conditions-for example, the malarial and scorbutic-should not be overlooked, and that the patient should not continue drinking the water in which the original infection was possibly conveyed, or remain exposed to any other source of infection which can be removed. As regards the medical treatment, $I$ venture to give a rough outline of the plan I adopted : Rest in bed. As much rest for the alimentary canal as is compatible with a sufficient supply of nourishment. Fomentations when necessary to relieve colic. Removal and prevention of accumulation in the bowels, and relief of engorgement by the administration of ipecacuanha, magnesium sulphate, or castor oil. When it can be borne, lavation of the large intestine by warm injections of permanganate of potash or boric acid, followed if needful by starch and opium enemata to relieve tenesmus. When the stools become fæcal, gradual substitution of intestinalantiseptics-bismuth salicylate or subnitrate, salol, resorcin, naphthol. If the ulcers appear to be slow in healing, astringent injections carefully administered. Tonics, and, where possible, change of air.

In one case, in which, fortunately, jnjections had not been recently used, death occurred from perforation, and in other fatal cases it was evident how little was needed to produce this issue.

In severe unresponding cases, care should be taken that the patient is not weakened by too protracted a course of ipecacuanha or magnesium sulphate. It is better to have earlier recourse to intestinal antiseptics, and to interrupt this treatment by the occasional readministration of either of the above drugs, should it seem to be desirable. As to opium, I believe the less it is used the better, though sometimes it has to be resorted to, and with good effect. In all severe cases, careful attention should be directed to the circulatory spstem.

The few cases of hepatic abscess I have seen followeù dysentery contracted in Central America. No case of hepatic abscess 